\title{
Biogas Purification Using Chitosan-Impregnated Porous Carbon
}

\author{
D P Rahmadani ${ }^{1}$, A Rahmada ${ }^{2}$, F Marendra ${ }^{2}$, H J Rimbawan ${ }^{2}$, R B Cahyono ${ }^{2,3}$, \\ Suherman $^{1}$, T Ariyanto ${ }^{2,3, *}$ \\ ${ }^{l}$ Department of Chemistry, Faculty of Mathematics and Natural Science, Universitas Gadjah Mada \\ ${ }^{2}$ Waste Refinery Center, Faculty of Engineering, Universitas Gadjah Mada, \\ ${ }^{3}$ Department of Chemical Engineering, Faculty of Engineering, Universitas Gadjah Mada \\ *Corresponding author. Email: teguh.ariyanto@ugm.ac.id
}

\begin{abstract}
Biogas is produced from the anaerobic digestion of biodegradable organic matter. However, its application is limited because it contains impurities such as carbon dioxide $\left(\mathrm{CO}_{2}\right)$ in high concentrations. Therefore, it is necessary to remove $\mathrm{CO}_{2}$ to improve the energy content of biogas. Porous adsorbents such as activated carbon have been widely used to remove $\mathrm{CO}_{2}$ from biogas. However, the performance of the split is limited, so the addition of active sites is required. In this research, chitosan impregnated porous carbon was used for biogas purification. Modification of porous carbon was made by impregnating chitosan on activated carbon with a ratio of chitosan to activated carbon of $0: 1,0.1: 1$, and $0.3: 1$. The success of the impregnation process of chitosan into activated carbon was analyzed from the results of characterization using Fourier Transform Infrared Spectroscopy (FTIR) and Scanning Electron Microscopy (SEM). Meanwhile, to determine the concentration of $\mathrm{CO}_{2}$ in biogas using Gas Chromatography (GC). The result showed that chitosan impregnated on activated carbon $(0.1: 1 \mathrm{w} / \mathrm{w})$ can purify biogas up to $95 \%$ compared to porous carbon.
\end{abstract}

\section{Keywords: Biogas purification, Chitosan, Impregnation, Porous carbon}

\section{INTRODUCTION}

Biogas is an alternative that is used to reduce the use of fossil fuels. Biogas is obtained by anaerobic digestion process of organic matter with the help of bacteria (sewage, animal by-products, agricultural, industrial and municipal solid waste) [1]. It is a mixture of gases mostly composed of methane $\left(\mathrm{CH}_{4}, 54-70 \%\right)$, carbon dioxide $\left(\mathrm{CO}_{2}, 27-45 \%\right)$, and traces of other gases such as $\mathrm{H}_{2} \mathrm{~S}, \mathrm{CO}, \mathrm{H}_{2}, \mathrm{O}_{2}$ or $\mathrm{N}_{2}$. The heat value of biogas is 4800-6900 $\mathrm{kcal} / \mathrm{m}^{3}$, compared to pure methane gas, which has a higher heating value up to $9100 \mathrm{kcal} / \mathrm{m}^{3}$ [2]. The quality of biogas is determined by the purity of $\mathrm{CH}_{4}$ gas [3]. Currently, there are several ways to remove $\mathrm{CO}_{2}$ from $\mathrm{CH}_{4}$. Adsorption technology has been carried out because of its cheap and easy method [4].

The adsorbent that has been widely used for biogas separation and purification is activated carbon. Activated carbon is very effective and inexpensive for gas adsorption, especially $\mathrm{CO}_{2}$ gas [5][6]. Nevertheless, activated carbon usually present low selectivity in the $\mathrm{CO}_{2} / \mathrm{CH}_{4}$ adsorption [7]. Therefore, it is necessary to make modifications to increase the effectiveness of $\mathrm{CO}_{2}$ gas adsorption in biogas. One of them is surface polarity modification to increase selectivity and chelating effect. Modifications are based on chemical interactions that can attract polar molecules into carbon.

The impregnation of amines is one method of impregnation that is often used. Yu et al.(2012) stated that the impregnation of amines in porous adsorbents is a method that can be increasing the rate of mass transfer of $\mathrm{CO}_{2}$ in adsorbents. This is due to addition of amine group that can provided specific adsorption sites and strong interactions [9]. Aroua et al. (2008) studied micropore-sized active carbon from coconut shells impregnated with polyethyleneimine $(\mathrm{PEI})$ as a $\mathrm{CO}_{2}$ adsorbent. The addition of amine groups to activated carbon has been shown to increase the $\mathrm{CO}_{2}$ adsorption capacity, where the adsorption capacity is ca. $4.2 \mathrm{~cm}^{3} \mathrm{~g}^{-}$ ${ }^{1}$. One natural compound that has many amine groups is the chitosan compound.

Chitosan is produced from biomass wastes with high nitrogen content and thus has been considered for $\mathrm{CO}_{2}$ capture via chemical adsorption (chemisorptions) with carbamate reaction [11]. Functionality and crosslinking help improve their chemical stability, while their 
mechanical strength is enhanced through physical modification which includes granulation and impregnation of the powder in a porous compound [12]. Fujiki and Yogo (2014) using chitosan in beads (PEI$\mathrm{CS})$ as $\mathrm{CO}_{2}$ adsorbent obtained results in the capacity of $\mathrm{CO}_{2}$ adsorbed at $2.3 \mathrm{mmol} \mathrm{g}^{-1}$ and $3.6 \mathrm{mmol} \mathrm{g}^{-1}$ if it involves water vapor.

This paper presents the effect of adding mass of chitosan in the manufacture of adsorbent beads chitosan impregnated activated carbon, the effect of contact time and biogas flow rate on the interaction of $\mathrm{CO}_{2}$ gas with adsorbents for biogas purification.

\section{MATERIAL AND METHODS}

\subsection{Materials}

Activated carbon from Haycrab Hayleys PLC (Sri Langka), Biogas Pasar Buah Gamping, the commercial chitosan its characteristics are as a degree of deacetylation is $94.8 \%$, acetic acid $\left(\mathrm{CH}_{3} \mathrm{COOH}\right) 2 \%$, and Sodium hydroxide $2 \mathrm{M}(\mathrm{NaOH})$ were obtained from Merck.

\subsection{Chitosan Impregnation onto Activated Carbon}

Chitosan solution was prepared by mixing $1 \mathrm{~g}$ of chitosan in $60 \mathrm{~mL}$ of $2 \%$ acetic acid. The chitosan solution was mixed with activated carbon for 4 hours at $185 \mathrm{rpm}$. The ratio of the amount of chitosan and carbon active is $0: 1,0.1: 1$, and $0.3: 1$. Hydrogel solution of chitosan active carbon mixture was dripped into $2 \mathrm{M}$ $\mathrm{NaOH}$ solution, so that the chitosan impregnated activated carbon beads formed. The composite beads of activated carbon impregnated with chitosan formed were filtered and washed with distilled water. At the final stage, the composite are preheated in a oven $55^{\circ} \mathrm{C}$ for 24 hours.

\subsection{Characterization}

All adsorbent samples were characterized by N2 (77 K) adsorption using Quadrasorb EVO/SI. The BET surface area was measured from adsorption isotherms using the Brunauer-Emmett-Teller equation. Functional groups on the material surface were investigated by FTIR spectrometer (Shimadzu FTIR 8201 PC). Images of the adsorbent surface were investigated by Scanning Electron Microscope (JSM-6510 LA).

\section{$2.4 \mathrm{CO}_{2}$ gas adsorption}

The $\mathrm{CO}_{2}$ gas adsorption process a PVC pipe with a diameter of $4.2 \mathrm{~cm}$ is prepared with a length of $20 \mathrm{~cm}$.
Into the adsorption column were included activated carbon and chitosan impregnated activated carbon. Respectively 60 grams were added in the adsorption column. Biogas has then flowed into the adsorbent column with a flow rate of $200 \mathrm{~mL}$ minutes $^{-1}$ for 3 minutes using a flowmeter. Biogas that comes out of the top of the adsorbent column analyzed using a GC instrument. To find out the effect of contact time on the adsorption process, the contact time was varied by 3,5 , 10,15 , and 20 minutes with a flow rate of $200 \mathrm{~mL}$ minutes $^{-1}$. flow rate variations of 50,125 and $200 \mathrm{~mL}$ minutes $^{-1}$ through the flowmeter for $3,5,10,15$, and 15 minutes were also carried out to determine the effect of the flow rate in the $\mathrm{CO}_{2}$ gas adsorption process.

\section{RESULTS AND DISCUSSION}

It has been recognized that activated carbon with the addition of active sites can affect the adsorption effect [14]. Due to the role of $\mathrm{CO}_{2}$ acid (weak Lewis acid), it is expected that the introduction of Lewis base to the activated carbon surface can support the $\mathrm{CO}_{2}$ capture performance of these materials. There are several ways that are widely used for the preparation of activated carbon. One popular way with basic enhancement is to remove or neutralize acid function or by replacing acid groups with the right base group as a basic nitrogen function. It has been shown that the introduction of functional groups of nitrogen to carbon surfaces can increase the active carbon capacity to the adsorbs $\mathrm{CO}_{2}$ [14-15, 16].

The chemical functional groups present in the chitosan, activated carbon, and chitosan-impregnated activated carbon materials are verified by Fourier infrared transforms (FTIR) spectroscopy in Fig.2. In the FTIR spectra for chitosan $(\mathrm{CH})$, the adsorption band around $3426 \mathrm{~cm}^{-1}$ is attributed to the stretching vibration of the $\mathrm{O}-\mathrm{H}$ groups, which overlaps the extension vibration of $\mathrm{N}-\mathrm{H}$ bond. The absorption region at wave number $1637 \mathrm{~cm}-1$ is the bending vibration of the $\mathrm{N}-\mathrm{H}$ bond on $\mathrm{NH}_{2}$ in chitosan. Also, the areas of 1381 and $1319 \mathrm{~cm}-1$ each showed angular symmetrical deformation vibrations from $\mathrm{CH}_{3}$ and axial $\mathrm{C}-\mathrm{N}$ deformations of the amino group.

The FTIR spectra of the activated carbon (AC) display absorption bands at $3426 \mathrm{~cm}^{-1}$ are attributed to the stretching vibration of the $\mathrm{O}-\mathrm{H}$ groups. The peaks at $2862 \mathrm{~cm}^{-1}$ are related to the $\mathrm{C}-\mathrm{H}$ bonds aliphatic and carboxylic groups. In addition, the peaks at $1628 \mathrm{~cm}^{-1}$ indicate the existence of $\mathrm{C}=\mathrm{O}$ in carbonyl and aromatic groups in AC. The absorption bands at $1474 \mathrm{~cm}^{-1}$ can be assigned as $\mathrm{C}-\mathrm{O}$ bonds stretching modes or $\mathrm{O}-\mathrm{H}$ deformation of the carboxylic acid. 


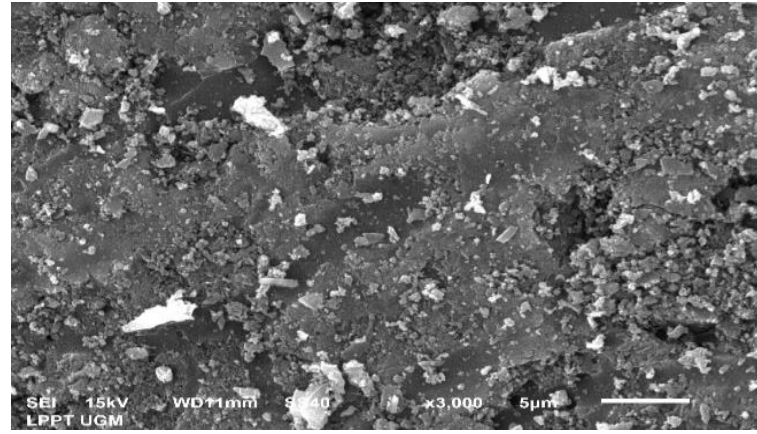

(a)

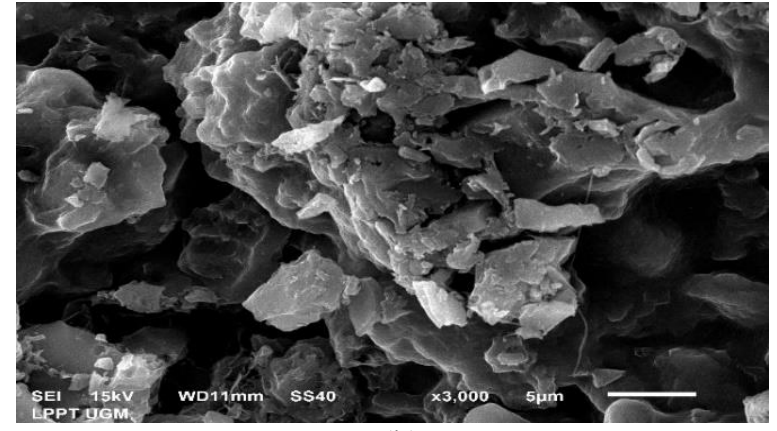

(b)

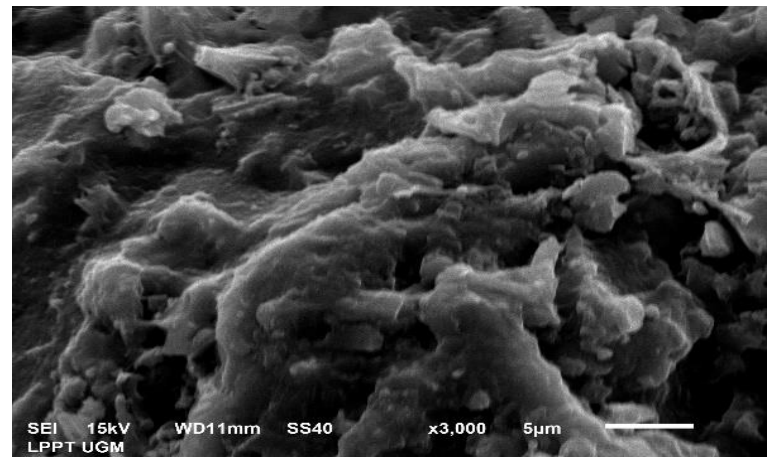

(c)

Figure $1 \mathrm{SEM}$ of (a) AC, (b) AC/CH $0.1 \mathrm{w} / \mathrm{w}$ (c) $\mathrm{AC} / \mathrm{CH} 0.3$ w/w.

The FTIR spectra of the chitosan impregnated activated carbon $(\mathrm{AC} / \mathrm{CH})$. This FTIR spectra results obtained are more similar to activated carbon spectra because the composition of activated carbon used in the synthesis process is more dominant than chitosan. However, it can be noticed that the bands assigned for carboxylic acids disappeared and the disappearance of the band could be attributed to the linkage between the carboxylic on the activated carbon surface and the ammonium ions of chitosan (Schiff bases). The band at $1636 \mathrm{~cm}^{-1}$ relates most probably to the bending vibrations from the $\mathrm{N}-\mathrm{H}$ bond to $\mathrm{NH}_{2}$ from chitosan and the $\mathrm{C}=\mathrm{N}$ stretching band of the Schiff base.There are several peaks in the absorption area 3433, 2924, and $2853 \mathrm{~cm}^{-1}$, where each of these uptakes shows successive vibrations of $\mathrm{O}-\mathrm{H}, \mathrm{C}-\mathrm{H}$ aliphatic stretching bonds, and $\mathrm{O}-\mathrm{CH}_{3}$ bonds in aldehyde groups. Also, the peak at $1435 \mathrm{~cm}^{-1}$ indicatevibrational stretching of the $\mathrm{C}-\mathrm{O}$ or $\mathrm{O}-\mathrm{H}$ deformation bonds to the carboxylic acid.

Table 1 reports the surface characteristic of the activated carbon and the chitosan impregnated activated carbon.
The surface morphologies of the activated carbon and chitosan impregnated activated carbon $0.1: 1$ and 0.3:1 w/w were compared using SEM at X 3000 magnification. The order of this magnification was enough to observe the pore structure on the activated carbon (Fig.1(a)). However, the coverage of chitosan on the surface of the impregnated activated carbon can be observed from the SEM image shown in Fig.1 (b) and (c).

Table 1. Surface characteristics of activated carbon and the chitosan impregnated activated carbon

\begin{tabular}{|c|c|}
\hline Samples & $\begin{array}{l}\text { BET surface area } \\
\qquad\left(\mathrm{m}^{2} \mathrm{~g}^{-1}\right)\end{array}$ \\
\hline$A C$ & 929 \\
\hline $\mathrm{AC} / \mathrm{CH} 0.1: 1 \mathrm{w} / \mathrm{w}$ & 654 \\
\hline $\begin{array}{c}\mathrm{AC} / \mathrm{CH} 0.3: 1 \\
\text { w/w }\end{array}$ & 646 \\
\hline
\end{tabular}

*BET: Brunauer-Emmett-Teller

The BET surface area of the chitosan impregnated activated carbon was reduced by the impregnation process. The BET surface area marginally decreased, 
indicating that a slight portion of the micropores was blocked.

\subsection{Effect of Chitosan Concentration}

Adsorption was carried out at a flow rate of $200 \mathrm{~mL}$ min-1 for 3 minutes with 60 grams the AC/CH 0.1 and $0.3 \mathrm{w} / \mathrm{w}$ and $\mathrm{AC}$ adsorbent. Based on Fig. 3 the optimum $\mathrm{CH}_{4}$ concentration of the three adsorbents used it is found that activated carbon impregnated with less chitosan $(0.1 \mathrm{w} / \mathrm{w})$ is better able to adsorb $\mathrm{CO}_{2}$ gas compared to activated carbon adsorbent impregnated with more chitosan.

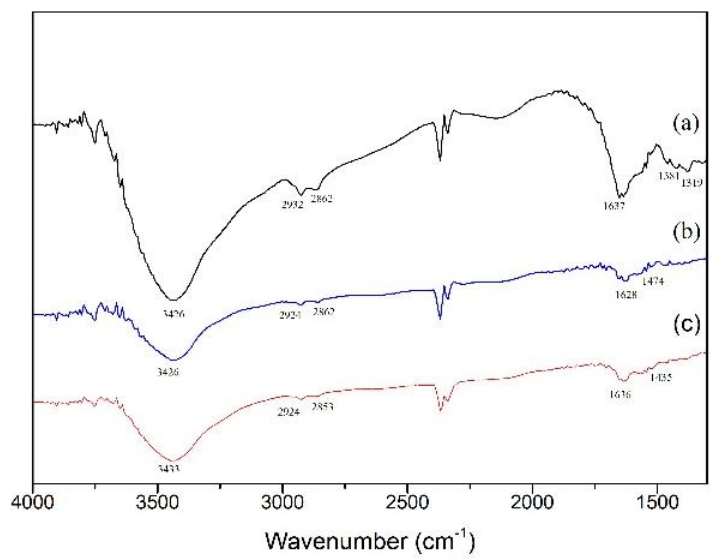

Figure 2 FTIR spectra of (a) chitosan, (b) activated carbon, (c) chitosan/activated carbon

\subsection{Effect of Contact Time}

Adsorption was carried out at a flow rate of $200 \mathrm{~mL}$ min-1 for various contact times $3,5,10,15$, dan 20 minutes with 60 gram the $\mathrm{AC} / \mathrm{CH} 0.1 \mathrm{w} / \mathrm{w}$ and $\mathrm{AC}$ adsorbent. Based on Fig.4 the optimum contact time is 3 minutes. The increased concentration of $\mathrm{CH}_{4}$ gas in biogas after the adsorption process is affected by the contact time, because the longer or increasing the contact time of $\mathrm{CO}_{2}$ gas with the adsorbent, the more gas volume passing through it will be more. This situation causes the interaction between the $\mathrm{CO}_{2}$ gas with chitosan impregnated activated carbon beads will increase because $\mathrm{CO}_{2}$ gas can be optimally adsorbed on the active site of the $\mathrm{AC} / \mathrm{CH}$ beads until it reaches its saturation point.

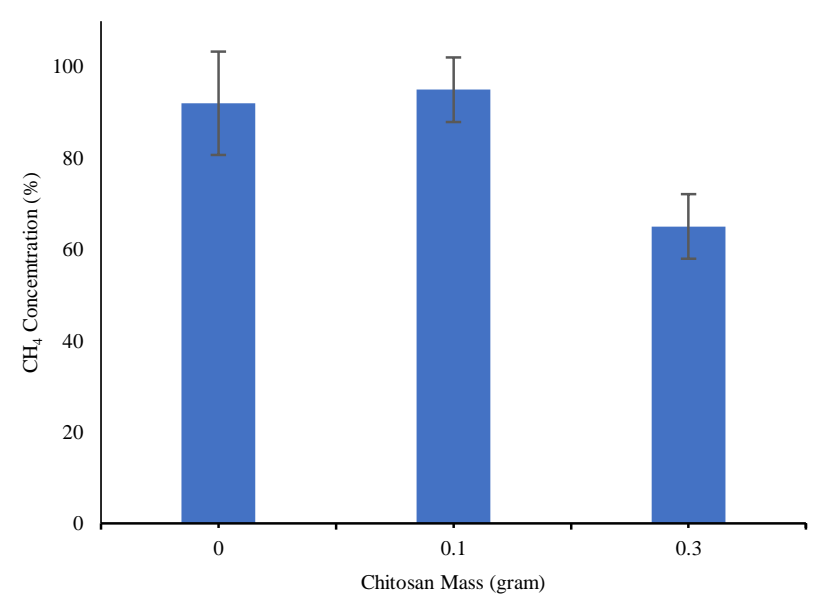

Figure 3 Effect of chitosan concentration on adsorption by adsorbent (conditions: $60 \mathrm{~g}$ adsorbent, $4.2 \mathrm{~cm}$ column diameter, $20 \mathrm{~cm}$ column height, and $200 \mathrm{~mL} / \mathrm{min}$ flow rate and time at 3 minutes)

\subsection{Effect of biogas flow rate}

Adsorption was carried out at a variableflow rate of 50,125 , and $200 \mathrm{~mL} \mathrm{~min}^{-1}$ and various contact times 3 , $5,10,15$, and 20 minutes with 60 grams the $\mathrm{AC} / \mathrm{CH} 0.1$ adsorbent. Based on Fig.5 the optimum $\mathrm{CH}_{4}$ gas concentration is obtained at a flow rate of $200 \mathrm{~mL} / \mathrm{min}$. The relatively small flow rate causes the time needed for biogas to pass through all the adsorbents in the column to be slower.

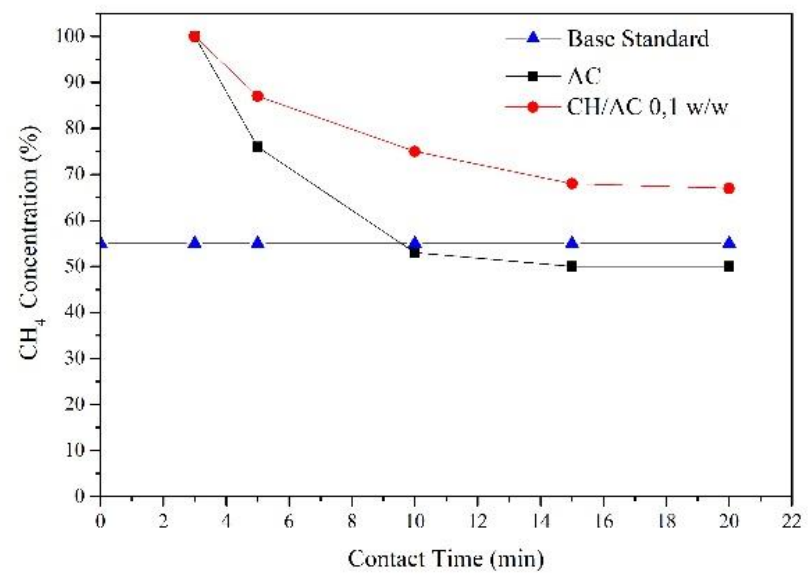

Figure 4 Effect of contact time on adsorption by adsorbent (conditions: $60 \mathrm{~g}$ adsorbent, $4.2 \mathrm{~cm}$ column diameter, $20 \mathrm{~cm}$ column heightand $200 \mathrm{~mL} / \mathrm{min}$ flow rate) 


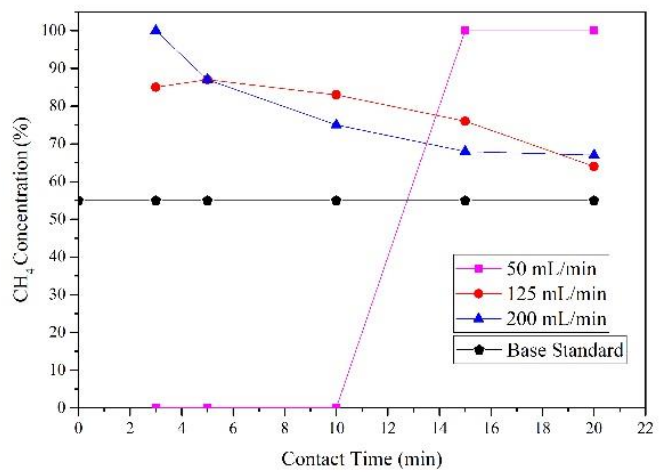

Figure 5 Effect of biogas flow rate on adsorption by adsorbent (conditions: $60 \mathrm{~g}$ adsorbent, $4.2 \mathrm{~cm}$ column diameter, $20 \mathrm{~cm}$ column height)

\section{CONCLUSION}

In this study, methods for producing activated carbon with a base surface were considered chitosan impregnated with activated carbon. The results showed that chitosan impregnated to activated carbon $(0.1: 1$ w/w) can purify biogas up to $95 \%$ compared to unmodified porous carbon.

\section{ACKNOWLEDGMENT}

The research was funded by Penelitian Terapan Unggulan Perguruan Tinggi (PTUPT) Program of Ministry of Research, Technology and Higher Education of the Republic of Indonesia (Grant No. 2709/UN1/DITLIT/DIT-LIT/LT/2019).The partnership in solid waste management between Waste Refinery Center-Universitas Gadjah Mada, Gemah Ripah Fruit Market and Environmental Services-Regency of Sleman, is gratefully acknowledged.

\section{REFERENCES}

[1] T Ariyanto, R B Cahyono, A Vente, S Mattheij, R Millati, Sarto, M J Taherzadeh, S Syamsiah, 2017, International Journal of Technology,8 (8), 13851392.
[2] Harasismowiczt M, Orluk P, Zakrzewska, Trznadel G and Chmielewski A G, 2007, Hazard. Matter, 144, 698-702.

[3] Kapdi S S, V K Vijay, S K Rajesh and Rajendra P, 2005, Renew. Energy, 30(8) ,1195-1202.

[4] Abatzoglou N and Boivin S, 2009, Biofuels, Bioprod, Biorefin,3, 42-71.

[5] Phalakornkule C, Foungchuen J and Pitakchon T, 2012, IJSEE, 3., 153-157.

[6] I Prasetyo, R Rochmadi, E Wahyono, T Ariyanto, 2017, Eng. J, 21 (4), 83-94.

[7] Khalil S H, M K Aroua and W M A W Daud, 2012, Chem. Eng. J., 183, 15-20.

[8] Yu C H, Huang C H, and Tan C S, 2012, Aerosol. Air. Qual. Res, 12, 745-769.

[9] Goel M, Sudhakar M S and Shahi M, 2015, Carbon Capture Storage and Utilization, (The Energy and Resources Institute, New Delhi, India).

[10] Aroua M K, Daud W M A W, Yin C Y and Adinata D, 2008, Sep. Purif. Technol, 62, 609-613.

[11] Zhao A, Samanta A, Sarkar P and GuptaR, 2013, Ind. Eng. Chem, 52, 6480-6491.

[12] Mallika P, A Himabindu and D Shailaja, 2006, J. Appl. Polym. Sci.63, 101.

[13] Fujiki J, and Yogo K, 2014, Energ. Fule., 28, 64676474.

[14] Pevida C, M Plaza, B Arias, J Fermeso and F Rubiera, 2008, J. Pis., 254, 7165-7172.

[15] Plaza M G, Pevida C, Arenillas A, Rubiera F and Pis J J, 2007, Fuel, 86, 2204-2212.

[16] Huang Y, P Chiueh C, C Shih, S Lo, L Sun, Y Zhong and C Qiu, 2015, Energy, 84, 75-82. 